\title{
The Behaviour of Diborane-Reduced Fulvic Acids in Flash Pyrolysis
}

\author{
Francisco Martin and Francisco J. Gonzàlez-Vila \\ Instituto de Recursos Naturales y Agrobiologia (C.S.I.C.) \\ Apartado 1052, 41080-Sevilla, Spain
}

\section{Abstract}

It is suggested that the striking structural changes introduced in humic substances by reduction with diborane may be useful in studying the role of carboxyl groups in the behaviour of these substances in flash pyrolysis. In the preliminary results shown in this communication, pyrograms of two fulvic acids of different origins and the corresponding diborane reduced substances are compared. It was found that the diborane reduction was responsible for both qualitative and quantitative changes in the pyrolytic patterns of the fulvic acids. These patterns reflect the changes in the reactivity and structural stability of the fulvic materials caused by the disappearance of the carboxyl groups.

\section{Introduction}

The progress in the application of analytical pyrolysis (Py) to the study of humic substances (HS) has been limited not only by technical factors [1], but mainly by the intrinsic complex chemical nature of these materials. This complexity has lead to serious difficulties in the interpretation of their complex pyrolytic patterns.

Recent reviews of the extense bibliography on this topic [2-5] show that Py, in combination with gas chromatography and mass spectrometry (Py-GC-MS, Py-MS), can be used as fingerprint techniques, illustrating the differences between humic fractions of various origin [6,7]. However, in contrast with the well known pathways of thermal breakdown of synthetic polymers [8], the mechanisms involved during the pyrolysis of HS are not completely understood.

The main structural information concerning the parent macromolecules obtained by Py is related to the identification of different components of the humic extracts. In fact, many typical Py-products of HS were recognized by comparison with those obtained by Py-GC-MS of well defined biopolymers [9-13].

Some approaches to the study of the Py mechanisms of HS have been carried out by examining the influence of chemical alterations of the humic molecules $[14,15]$. The specific modification of carboxyl groups $(\mathrm{COOH})$, usually based on the preparation of ester derivatives, has not always been satisfactorily accomplished. In general, the esterification conditions are either too drastic (when methanol-HCl is used) or suffer from poor yields and non-specificity, when diazomethane is employed. 
In a previous study [16] we were able to obtain stable FA preparations in the reduced state upon treatment with diborane in tetrahydrofuran (THF). The diborane treatment was found to be a useful method to obtain chemically transformed HS without carboxyl groups. This striking alteration is responsible for changes not only in the solubility and colloidal properties of this transformed HS, but probably also in the nature of the different intramolecular forces affecting the structural arrangement of the macromolecular constituents. Therefore, it is expected that the comparison by $\mathrm{Py}-\mathrm{GC}-\mathrm{MS}$ of original and reduced humic samples can provide information on the effects of carboxyl functionality upon the behaviour of HS against thermal degradation.

\section{Materials and Methods}

Two fulvic acids isolated from a podzol soil (FA-P) and from the lake water over a peatland (FA-W) were investigated. The processes for extraction and purification, as well as the physico-chemical characteristics of these samples have been reported elsewhere $[17,18]$.

The treatment of the samples with diborane in THF to obtain the reduced preparations has been previously described [16]. Briefly, the samples were dissolved in a minimum amount of THF, and $5 \mathrm{ml}$ of a $1 \mathrm{M}$ solution of diborane in THF (Aldrich) was slowly added under $\mathrm{N}_{2}$ atmosphere at a temperature of $0^{\circ} \mathrm{C}$. Additional amounts of diborane in THF were added periodically until hydrogen evolution was completed; the flask was stoppered under $\mathrm{N}_{2}$ and heated to $50^{\circ} \mathrm{C}$. After 20 days, the excess of diborane was destroyed by the addition of water; the tetrahydrofuran was evaporated under reduced pressure, and the boric acid formed was removed by the successive evaporation in the presence of methanol. The efficiency of the reaction was confirmed by the more or less complete disappearance of the carbonyl stretching absorption at $1720 \mathrm{~cm}^{-1}$ in the IR spectra, and the disappearance of the resonances for carboxyl carbons at about $175 \mathrm{ppm}$, in the ${ }^{13} \mathrm{C} \mathrm{NMR}$ spectra.

\section{Pyrolysis Conditions}

The pyrolysis was carried out at $700^{\circ} \mathrm{C}$ in a CDS Pyroprobe 190 consisting of a Pt coil heated by an electric current at a rate of up to $20^{\circ} \mathrm{C} / \mathrm{msec}^{-1}$. The sample $(2 \mathrm{mg})$ was placed in a quartz tube, using quartz wool for end plugs. The pyrolysis unit was manted in the injection block of a HP 5730A gas chromatograph, or on a HP 5992B in the case of the Py-GC-MS system, through the resistively heated special device shown in Fig. 1, which allows the horizontal insertion of the pyrolyzer.

The volatile Py products were separated on a $25 \mathrm{~m}$ cross-linked fused silica column (i.d. $=0.32 \mathrm{~mm})$ coated with $\mathrm{OV}-101(0.11 \mu \mathrm{m}$ film thickness). Before starting the pyrolysis temperature program, a pre-heating of the pyrolysis unit at $250^{\circ} \mathrm{C}$ for $10 \mathrm{~min}$ allowed adhered lipid material to be removed, channeling any evolved material directly to the purge vent. The Py products were first concentrated in a loop of the column into a liquid $\mathrm{N}_{2}$ cold trap and then the $\mathrm{GC}$ oven was heated from 40 to $300^{\circ} \mathrm{C}$ at a rate of $6^{\circ} \mathrm{C} / \mathrm{min}$. The Py products were identified by comparing their EI mass spectra with mass spectra libraries, and with mass spectra and GC retention times of standard compounds 


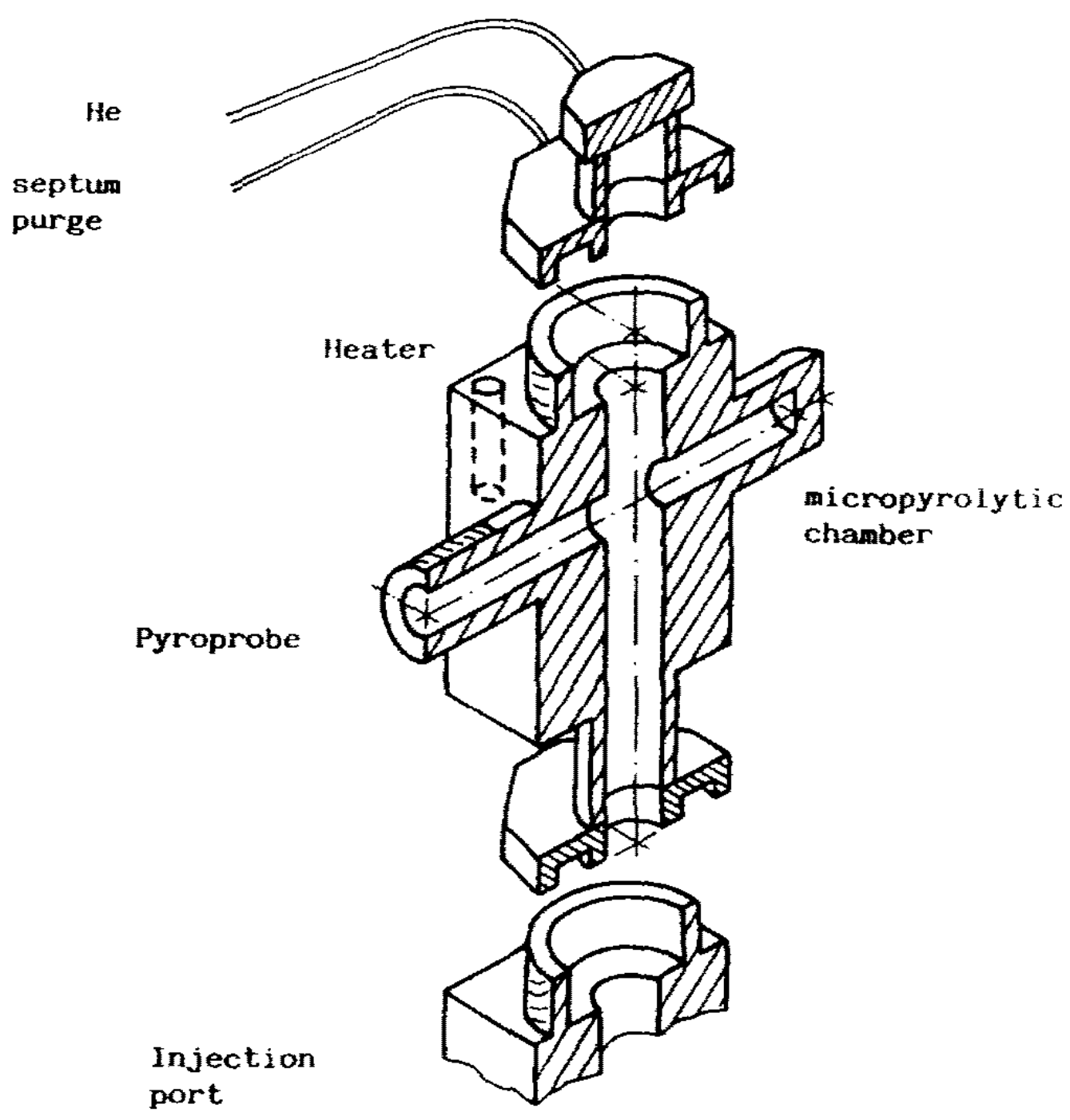

Figure 1 Expanded view of the pyrolytic accessory.

\section{Results and Discussion}

The great qualitative and quantitative differences between the pyrolytic patterns yielded by the original and diborane-reduced samples are evident (Figs 2 and 3). The original samples gave relatively simple pyrograms, as is usual for these humic fractions [17], whereas the reduced samples yielded complex chromatograms. With some exceptions identification of the Py compounds in the pyrograms was achieved (Table 1). There

main series of compounds present, before and after diborane reduction. This exclusion is possible, since a detailed description of the identified compounds is not required in order to characterize the changes occurring upon reduction. Only significative peaks are labelled in the Figs 2 and 3 to illustrate the different nature of the Py products.

The Py products encountered in the original samples were very similar to those previously described [5, and references therein]. The podzol FA (FA-P), as other soil FA's, yielded mainly Py products from polysaccharides, together with some aromatic compounds from lignins and dialkyl phthalates. No nitrogen derivatives were identified. The FA-W gave a similar pattern of Py products, with a higher proportion of aromatic compounds, whereas dialkyl phthalates were not frequently encountered. 
Table 1 Series of Py products identified in the original and reduced samples.

FA-P

Low b.p. compounds

n-alkanes (C8-C33)

Branched hydrocarbons

Furan,furfural,benzo-

furan derivatives

Aromatic compounds

from lignins

Hydroaromatics

Alkyl benzenes

Alkyl naphthalenes

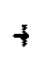

FA-P-R

$\begin{array}{rrrr}+ & +++ & + & +++ \\ + & ++ & + & ++\end{array}$

$+$

$+\quad+$

$+2+$

- +

$+\quad+$



FA-W

FA-W-R

$\begin{array}{rrr}+ & +r \\ + & + & + \\ + & ++ \\ + & ++\end{array}$

not detected

,,++++++ : low, medium and high presence

The reduced preparations (FA-P-R and FA-W-R) gave different types and amounts of Py products. In both cases the predominant components were series of multibranched aliphatic and aromatic hydrocarbons (labelled $a$ and $b$ in the chromatograms); the former were predominant in FA-P-R and the latter in the FA-W-R.

It is suggested that the loss of functionality leads to "more easily pyrolyzable samples", and these samples with a lower oxygen content yield higher relative amounts of Py products. These data are in agreement with the previous observations of Bracewell et al. [19] on the transformations occurring during the Py of organic matter from surface organic horizons. They found that, upon Py, raw humus originating from a retarded humification process involving the selective removal of functional groups containing oxygen and nitrogen, yielded high amounts of hydrocarbons. Py should also cause aromatic moieties from lignins and amino acids to lose functional groups and thereby yield aromatic hydrocarbons. However, aromatic hydrocarbons can also arise, by cyclisation of highly unsaturated chains, which can be formed during Py by elimination of electron-withdrawing side groups, such as hydroxyl and carboxyl groups [20].

Another explanation could be that the reductive treatment has progressed to complete. the conversion of $\mathrm{COOH}$ into $\mathrm{CH}_{3}$ groups. This would mean that after pyrolysis there would be more possibilities for alkyl rearrangements and reactions among alkyl radicals in the reduced samples. In fact, when appropriate electron-donating groups are present, complete reduction of $\mathrm{COOH}$ to a methyl group is possible [21]. Thus, studies of the diborane reduction of indole and pyrrole carbonyl derivatives, and of other "electronrich" aromatic carbonyl compounds, showed that the carbonyl group was completely reduced to a methylene group [22].

From the studied samples it was not possible to select the most significant compounds to monitor the particular behaviour of some humus components. In general, all the 


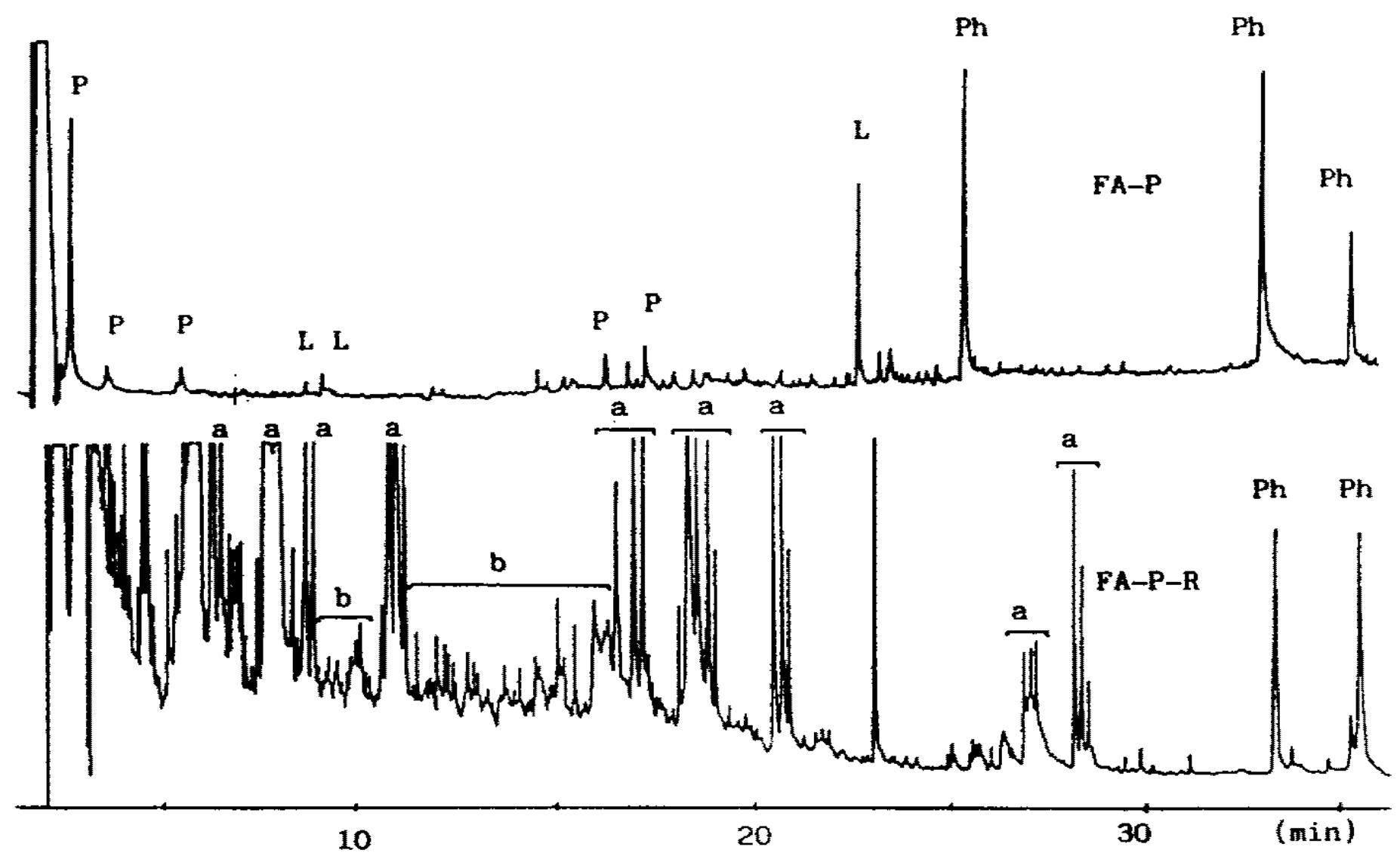

Figure 2 Pyrograms of the Podzol fulvic acid before (FA.P) and after (FA-P-R) the reductive treatment. Py-products characteristic for polysaccharides (P), lignin (L), dialkyl phthalates (Ph). multibranched aliphatic (a) and aromatic (b) hydrocarbons are indicated.



FIgure 3 Pyrograms of the peat water fulvic acid belore (FA-W) and after (FA-W-R) the reductive treatment. Labelled compounds as in Fig. 2. 
identified compounds in the original samples were also present in the pyrograms of the reduced samples. Therefore, the diborane treatment does not apparently affect the polysaccharide moieties responsible for most of the Py products of the original samples. The present results should, however, be corroborated by further investigations with model compounds. Until now it has been demonstrated that the application of the hydroboration reaction to carbohydrates containing either a terminal or an endocyclic double bond yielded only hydration products [23].

The evolution of nitrogen compounds arising from Py of polypeptides would be very interesting, since several authors have shown that the treatment with diborane can be adapted for the specific reduction of carboxyl groups in amino acids, peptides and proteins $[24,25]$ without affecting the peptide bonds. Investigations on the particular behaviour of nitrogen-containing Py products are currently in progress.

\section{References}

1. Montaudo, G. J. Anal. Appl. Pyrol. 13:1 (1988).

2. Irwing, W.J. Analytical Pyrolysis (New York: Marcel Dekker, 1982).

3. Meuzelaar, H.L.C., J. Haverkamp and F.D. Hileman. Pyrolysis Mass Spectrometry of Recent and Fossil Biomaterials (Amsterdam: Elsevier, 1982).

4. Larter, S.R. In: K.J. Voorkees, Ed., Analytical Pyrolysis. Techniques and Applications, p.212 (London: Butterworths, 1984).

5. Saiz-Jimenez, C. Origin and Chemical Nature of Soil Organic Matter. Ph.D. Diss. (Delft: University Press, 1988).

6. Wilson, M.A., R.P. Philp, A.H. Gillan, T.D. Gilbert and K.R. Tate. Geochim. Cosmochim. Acta 47:497 (1983).

7. Saiz-Jimenez, C. and J.W. de Leeuw. J. Anal. Appl. Pyrol. 9:99 (1986).

8. Albright, L.F., B.L. Crynes and W.H. Corcoran, Eds. Pyrolysis: Theory and Industrial Practice (New York : Academic Press, 1983).

9. Sigleo, A.C. Science 200:1054 (1978).

10. Martin, F., C. Saiz-Jimenez and F.J. Gonzalez-Vila. Holzforschung 33:210 (1979).

11. Obst, J.R. J. Wood Chem. Technol. 3:377 (1983).

12. van der Kaaden, A., J. Kaverkamp, J.J. Boon and J.W. de Leeuw. J. Anal. Appl. Pyrol. 5:199 (1983).

13. van der Kaaden, A., J.J. Boon, J.W. de Leeuw, F. de Lange, P.J.W. Schuyl, H.R. Schulten and U. Bahr. Anal. Chem 56:2160 (1984).

14. Martin, F. and Gonzalez-Vila, F.J. Z. Pflanzenernhr. Bodenk. 146:653 (1983).

15. Saiz-Jimenez, C. and J.W. de Leeuw. J. Anal. Appl. Pyrol. 11:357 (1987).

16. Martin, F., F.J. Gonzalez-Vila and G. Almendros. Sci. Tot. Environ. 62:121 (1987).

17. Martin, F. and F.J. Gonzalez-Vila. Z. Pflanzenernhr. Bodenk. 146:409 (1983).

18. Martin, F. and F.J. Gonzalez-Vila. Chem. Geol. 67:353 (1988).

19. Bracewell, J.M. and G.W. Robertson. Geoderma 40:333 (1987). 
20. Bracewell, J.M., G.W. Robertson and B.L. Williams. J. Anal. Appl. Pyrol. 2:239 (1980).

21. Lane, C.F. Aldrichimica Acta 10:41 (1977).

22. Biswas, K.M. and A.H. Jackson. Tetrahedron 24:1145 (1968).

23. Rosenthal, A.F. and M. Sprinzl. Carbohyd. Res. 16:337 (1971).

24. Rosenthal, A.F. and M.Z. Atassi. Biochim. Biophys. Acta 3:410 (1967).

25. Atassi, M.Z. and A.F. Rosenthal. Biochem. J. 111: 593 (1969) . 